\title{
Oriar Éducaçãa
}

\section{SERVIÇO SOCIAL E EDUCAÇÃO: A EXPERIÊNCIA DO TRABALHO SOCIOEDUCATIVO NO MUNICÍPIO DE BALNEÁRIO CAMBORIÚ/SC}

OLIVEIRA ,Patrícia da Costa ${ }^{1}$

Resumo: O presente artigo busca apresentar um resgate histórico do trabalho do Serviço Social desenvolvido no decorrer dos anos no município de Balneário Camboriú. Volta-se para o estudo da relação entre o Serviço Social e a política educacional no âmbito da Educação Infantil, procurando contextualizar o leitor sobre os desafios impostos hoje à categoria profissional, que materializam os anseios e perspectivas profissionais daqueles inseridos na política educacional. Para compreender esta questão, realizamos um estudo bibliográfico e aplicação de um questionário às gestoras dos Núcleos de Educação Infantil do município. Percebe-se a necessidade e o fortalecimento do Serviço Social educacional no decorrer dos anos, com vistas à promoção e prevenção das expressões do trabalho social, como as questões relativas aos processos de desenvolvimento e aprendizagem das crianças dos Núcleos de Educação Infantil do município de Balneário Camboriú.

Palavras-Chaves: Educação, Serviço Social, Educação Infantil.

Abstract: This article seeks to present a historical review of the Social Services work over the years in the city of Camboriú. He turns to the study of the relationship between social work and educational policy on Early Childhood Education, seeking to contextualize the reader about the challenges posed today to the professional category, which embody the aspirations and professional prospects of those entered in educational policy. To understand this issue, we conducted a bibliographic study and application of a questionnaire to the management of the municipality of Child Education Centers. You see the need and the strengthening of educational social work over the years, with a view to promoting and prevention of expressions of social work, such as issues relating to

\footnotetext{
${ }^{1}$ Mestre em Educação e Bacharel em Serviço Social pela UNISUL - Universidade do Sul de Santa Catarina. Especializanda em Gênero e Diversidade na Escola pela UFSC - Universidade Federal de Santa Catarina. Integrante do Grupo de Pesquisa Educação, Infância e Gênero - GEDIG. E-mail: patrícia.asocial@hotmail.com.br
}

UNESC, Criciúma, v. 5, n¹, janeiro/Junho 2016. Criar Educação - PPGE - UNESC 


\section{Criar Éducação}

the development and learning of children from Early Childhood Education Centers in the city of Balneario Camboriú.

Key Words: Education, Social Services, Early Childhood Education.

\section{Introdução}

A análise em questão objetiva apresentar um resgate histórico da inserção do Serviço Social na rede educacional do município de Balneário Camboriú, e de que forma o Serviço Social tem contribuído significativamente para a construção da política educacional e com melhorias na relação entre família e escola. O Serviço Social é responsável pelo estudo de indicadores socioeconômicos que constituem a realidade sociofamiliar das crianças inseridas nos Núcleos de Educação Infantil, propondo e executando mecanismos com vistas à orientação e integração família $\mathrm{x}$ escola; e que assegure a garantia do direito ao acesso e permanência na educação.

Exige-se da educação, na contemporaneidade, um comprometimento com as mudanças e transformações sociais, tendo como princípio balizador uma educação atenta aos olhares da diversidade, múltiplas linguagens, e que se constitua a partir da correlação de forças sociais existente na sociedade. Assim, tais processos colocam-se desafiadores à formação docente, uma vez que se relacionam com o futuro da educação e da própria sociedade brasileira. Diante das mudanças ocorridas nas políticas públicas em nosso país, é vital a experimentação de um projeto político e educacional que se firme em bases consistentes.

Assim, para compreender esta questão, realizamos um estudo bibliográfico e aplicação de um questionário para as gestoras dos Núcleos de Educação Infantil, enquanto representantes da comunidade escolar no município, com o objetivo de avaliar o desenvolvimento do trabalho social nos últimos anos.

\section{Serviço Social e Educação na primeira infância}

A Educação Infantil passou a fazer parte da Educação Básica no Brasil, a partir da promulgação da Lei de Diretrizes e Bases da Educação Nacional - LDB (9.394/1996). Desde então se percebeu, no cenário nacional, o aumento das 


\section{Criar Éducaçãa}

pesquisas, normativas e produções que validam a necessidade de mais qualificação para esta etapa da educação. Desde a criação da LDB em 1996, quando a Educação Infantil passou a integrar a Educação Básica, muito se tem produzido visando a normatizar e qualificar essa etapa da educação.

A demanda de atendimento para a primeira infância envolve-se em um complexo processo educacional e acaba por envolver políticas sociais e setores indistintamente, como a educação, saúde, nutrição assistência social e proteção de direitos.

A Constituição Brasileira de 1988, considerada a constituição cidadã, é um dos maiores avanços na incorporação das políticas públicas enquanto responsabilidade do Estado, atendendo às históricas reivindicações das classes trabalhadoras. Nessa direção, a Constituição preconiza e define princípios da seguridade social (art. ${ }^{0}$ 194), enfatizando a "Doutrina de Proteção Integral" ${ }^{2}$ social prestada às famílias, às crianças e aos adolescentes, aos deficientes e aos idosos no âmbito da seguridade social, que devem ser atendidos por intermédio de políticas públicas. No caso da população infanto-juvenil, a define em seu art.o 227 e, posteriormente, pelo advento do Estatuto da criança e do Adolescente (Lei 8.069/1990, alterado pela Lei 12.010/2009):

Art. $4^{\circ}$ é dever da família, da comunidade, da sociedade em geral e do poder público, assegurar com absoluta prioridade, a efetivação dos direitos referentes à vida, a saúde, à alimentação, à educação, ao esporte, ao lazer, à profissionalização, à cultura, à dignidade, ao respeito, à liberdade e a convivência familiar e comunitária (BRASIL, 1990).

Em relação à garantia de direitos, o Estatuto da Criança e do Adolescente estabelece que:

Art. $3^{\circ}$ A criança e o adolescente gozam de todos os direitos fundamentais inerentes à pessoa humana, sem prejuízo da proteção integral de que trata esta Lei, assegurando-se-lhes, por lei ou por outros meios, todas as oportunidades e facilidades, a fim de lhes facultar o desenvolvimento físico, mental, moral, espiritual e social, em condições de liberdade e de dignidade. Art. $4^{\circ}$ É dever da família, da comunidade, da sociedade em geral e do poder público assegurar, com absoluta prioridade, a efetivação dos direitos referentes à vida, à saúde, à alimentação, à educação, ao esporte, ao lazer, à profissionalização, à cultura, à dignidade, ao respeito, à liberdade e à convivência familiar e comunitária (BRASIL, 1990).

\footnotetext{
${ }^{2}$ A "Doutrina da Proteção Integral" é a fundamentação jurídica do subsistema de direitos da criança e do adolescente, em âmbito nacional; no entanto tem sua origem na "Convenção Internacional dos Direitos da Criança”, estando seu conteúdo presente nos demais documentos normativos das Nações Unidas voltados para a área de crianças e adolescentes (BRASIL, 2012, p. 30)
}

UNESC, Criciúma, v. 5, n¹, janeiro/Junho 2016. Criar Educação - PPGE - UNESC 


\section{Criar Éducação}

\section{Consoante ao exposto, é necessário compreender a criança e o} adolescente como sujeitos em formação, com direitos garantidos desde o período pré-uterino. No que diz respeito à educação, a LDB(1996) estabelece que :

Art. $4^{\circ} \mathrm{O}$ dever do Estado com educação escolar pública será efetivado mediante a garantia de: I - educação básica obrigatória e gratuita dos 4 (quatro) aos 17 (dezessete) anos de idade, organizada da seguinte forma: a) pré-escola; b) ensino fundamental; c) ensino médio; II - educação infantil gratuita às crianças de até 5 (cinco) anos de idade; [...] (BRASIL, 1996).

A Educação Infantil, enquanto primeira etapa da Educação Básica, é considerada vital para o pleno desenvolvimento infantil. Todavia, nesta perspectiva, compreende-se pelo conceito traduzido nas Diretrizes Curriculares Nacionais da Educação Infantil (BRASIL, 2010, p. 12) que

[...] se caracterizam como espaços institucionais não domésticos que constituem estabelecimentos educacionais públicos ou privados que educam e cuidam de crianças de 0 a 5 anos de idade no período diurno, em jornada integral ou parcial, regulados e supervisionados por órgão competente do sistema de ensino e submetidos a controle social.

Este documento é referência para o planejamento das ações na Educação Infantil e indica uma série de princípios essenciais para orientação do trabalho pedagógico nas instituições que possuem essa modalidade de ensino. Dentre eles destacamos:

Éticos: da autonomia, da responsabilidade, da solidariedade e do respeito ao bem comum, ao meio ambiente e às diferentes culturas, identidades e singularidades;

Políticos: dos direitos de cidadania, do exercício da criticidade e do respeito à ordem democrática;

Estéticos: da sensibilidade, da criatividade, da ludicidade e da liberdade de expressão nas diferentes manifestações artísticas e culturais (BRASIL, 2010).

No município de Balneário Camboriú observa-se o amparo em documentos nacionais e municipais que regulamentam as diretrizes educacionais na Educação Básica. Conforme dados obtidos em contato com a Secretaria Municipal de Educação - Departamento Infantil, atualmente o município conta com 4.056 crianças inseridas na Educação Infantil, dentre essas 2.868 na faixa etária de 0-3 anos, e 2.343 de 4-5 anos. Entende-se que educar e cuidar são gestos indissociáveis de promoção educacional das crianças pequenas, sendo duas ações separadas na origem dos serviços de atenção a essas crianças. 


\section{Criar Éducação}

ediunesc unesc

$\mathrm{Na}$ integração dessas faces, as Diretrizes Curriculares para Educação Infantil (BRASIL, 2010, p. 18) definem que:

A proposta pedagógica das instituições de Educação Infantil deve ter como objetivo principal promover o desenvolvimento integral das crianças de zero a cinco anos de idade garantindo a cada uma delas o acesso a processos de construção de conhecimentos e a aprendizagem de diferentes linguagens, assim como o direito à proteção, à saúde, à liberdade, ao respeito, à dignidade, à brincadeira, à convivência e interação com outras crianças.

A educação é entendida como direito social inerente ao cidadão brasileiro e, desta forma, tem a função formativa do indivíduo intervindo diretamente na constituição da sua identidade. Gentili (2009) reconhece que a educação é um direito humano, um bem público e social a partir da análise da Declaração Universal dos Direitos Humanos de 1948, que nos ajuda a nos reconhecermos como seres humanos livres, iguais e com direitos para lutar contra toda forma de exclusão, "[...] A educação protege-nos e é a defesa de nossa identidade [...]" (p.1072) Portanto, a educação que visa à transformação busca entender as mudanças na contemporaneidade e abandona valores culturais que enfatizem o preconceito e discriminação social.

Ao longo dos tempos, a transformação da educação permitiu que esta fosse vista como um direito, desfazendo-se dos antigos preceitos paternalistas. A luta pela educação amplia o acesso à cidadania e democratiza os saberes, como possibilidade de desalienação da população, prevê, então, "[...] a educação como um processo de humanização dos sujeitos coletivos diversos [...]" (ARROYO, 2003, p. 34).

Nesse sentido, sabemos que a Educação Infantil possui uma diversidade de propostas pedagógicas que estão em constante transformação. Cada vez mais as crianças pequenas estão sendo inseridas nesta modalidade de ensino, sendo necessário que a instituição e seus profissionais estejam aptos a promover ações de estimulação das crianças, corroborando no processo de desenvolvimento destas.

Em uma perspectiva histórica, Oliveira (2002, p. 43) pondera que:

[...] a creche, historicamente vista como refúgio assistencial para a população infantil desprovida de cuidados domésticos, tem definido a infância como uma questão de ordem privada e não tem considerado devidamente a comunidade maior como co-responsável pela educação dos pequenos. Nessa ótica, o peso recai todo sobre a família. A creche se 


\section{Criar Éducação}

apresenta apenas como sua substituta, limitando-se a desenvolver atividades que restringem o olhar da criança a uma esfera muito imediata. Com isso tem construído um retrato da infância descolado de sua sociedade e de sua cultura específicas.

Contudo, esse paradigma da visão de criança e infância vem se modificando na premissa da recusa de práticas meramente assistenciais de cuidados para uma educação da infância. Nas palavras de Machado (2008, p. 26), "[...] um certo campo consensual em torno do valor educativo da instituição de educação infantil a partir da valorização de algumas premissas básicas, entre as quais o reconhecimento da competência da criança desde recém-nascida”.

\section{O Trabalho do Serviço Social na Educação Infantil no município de Balneário Camboriú-SC}

O trabalho do serviço social no âmbito educacional consiste na promoção que visa a permear a importância entre a relação democracia versus cidadania, sobretudo no conjunto de importância que a educação atinge nas esferas de políticas sociais no curso do desenvolvimento do Estado e sociedade civil. Conforme entendimento de lamamoto (2005), o trabalho da assistente social, no âmbito educacional, contribui para o exercício da cidadania e efetivação dos direitos ao exigir, da profissional, o desafio de "desenvolver sua capacidade de decifrar a realidade e construir propostas de trabalho criativas e capazes de preservar direitos a partir de demandas emergentes no cotidiano. Enfim, ser um profissional propositivo e não só executivo" (IAMAMOTO, 2005, p. 20).

A Educação assume um papel central no âmbito das lutas sociais e na relação da construção da democracia. No entendimento de Almeida (2003), o Serviço Social presente na política educacional não é algo recente, mas ainda é muito tímida sua inserção na maioria dos municípios do país. Para o autor, a inserção da assistente social neste campo deve-se a três tendências a partir dos anos 80, a saber: a) o enfrentamento da pobreza pela ascensão das políticas sociais que estabelecem a condicionalidade central na educação; b) a afirmação crescente da educação escolarizada de forma universal, tornando-se um marco nos direitos das crianças e dos adolescentes com interface nas políticas setoriais voltadas aos segmentos sociais em situação de vulnerabilidade; e c) a compreensão da educação 


\section{Criar Éducação}

enquanto direito humano, que permite organizar as práticas sociais em torno de processos formativos do ser humano, propondo uma arena de disputas ideológicas mobilizadas pelos paradigmas educacionais no âmbito do Estado e da sociedade civil, como empreendedorismo, empregabilidade e emancipação.

Pensar a atuação da assistente social nesta política requer um olhar sobre a práxis profissional e social diante das dimensões socioeducativas da profissão. Por isto, envolve a compreensão da complexidade e dinamicidade da sociedade e do campo de atuação.

No ano de 2013, a profissional que atuava na Educação Infantil no município de Balneário Camboriú realizou uma entrevista com as gestoras dos 26 núcleos de educação infantil, avaliando o fechamento de um ciclo de cinco anos de inserção do Serviço Social nesta modalidade de ensino. Contamos com a participação de 26 gestoras e cada uma delas respondeu as quatro questões propostas, que relacionam a percepção do trabalho do Serviço Social; percepção do atendimento da rede de proteção à criança no município; ocorrências relacionadas às crianças nos núcleos e temáticas essenciais para futuras formações. No decorrer desta análise descreveremos algumas respostas do questionário aplicado na pesquisa.

Destarte, Almeida (2007, p. 05) argumenta que os assistentes sociais “[...] devem expressar uma das estratégias de enfrentamento desta realidade na medida, em que represente uma lógica mais ampla de organização do trabalho coletivo na esfera da política educacional, seja no interior das suas unidades educacionais, das suas unidades gerenciais [...]", ou seja, cabe ao profissional propor estratégias e práticas de articulação coletiva com as políticas setoriais.

Com base nos registros encontrados no caderno Orientações Curriculares da Educação Infantil do município de Balneário Camboriú (2013), a Secretaria Municipal de Educação de Balneário Camboriú contou com a inserção do profissional de Serviço Social na rede de profissionais da educação no ano de 2009. Neste ano, a assistente social inseriu-se na educação desenvolvendo suas atividades nos vinte e três NEI - Núcleos de Educação Infantil; posteriormente, em 2013, o quadro de equipe foi ampliado para mais uma assistente social inserida no Departamento Técnico-Pedagógico, tendo como referência os dezesseis CEM - Centros Educacionais Municipais.

UNESC, Criciúma, v. 5, n¹, janeiro/Junho 2016. Criar Educação - PPGE - UNESC 


\section{Criar Éducação}

Segundo a autora Corrêia (2013, p. 91) identificou, as primeiras atividades do Serviço Social direcionaram-se para o esclarecimento das atribuições e competências da assistente social no âmbito educacional para os/as professores, especialistas em educação e demais técnicos de suporte, como fonoaudiólogos/as e psicólogos/as. Com o decorrer do aprimoramento profissional foi possível compreender a relação dos Núcleos de Educação Infantil com as crianças e os familiares para posterior proposta de intervenção.

Conforme preconiza o Referencial Curricular Nacional para Educação Infantil (BRASIL, 1998b), torna-se necessária a compreensão de que as unidades de Educação Infantil e família possuem papeis complementares na construção dos processos educativos das crianças, uma vez que ambas formam um círculo de confiança e constroem os referenciais próprios do desenvolvimento infantil, como interação com o próximo, identidade, aspectos cognitivos e motores. Considerando tais fatores, é importante que se estabeleça uma dinâmica relacional saudável com as famílias.

Fernandes (2012), ao analisar a obra de Aldo Fortunati $A$ educação infantil como um projeto da comunidade: crianças, educadores e pais nos novos serviços para a infância e a família, descreve como destaque a relevância do papel da família como condicionante para educação de qualidade: "[...] alerta que os serviços educativos destinados às crianças devem ter espaço constante e diferenciado aos pais, auxiliando-os na construção de sua paternidade/maternidade. [...] San Miniato mantém constantes diálogo entre pais e professores [...]" (FERNANDES, 2012, p. 259, grifos do autor).

Em falas das entrevistadas na pesquisa realizada no ano de 2013, quando questionadas sobre a percepção do trabalho do Serviço Social na Educação Infantil, registramos:

Por vários momentos que o NEl- Bom Sucesso necessitou do trabalho do Serviço Social, foi percebido a parceria, o auxílio, o caminho correto a ser seguido. Parceria entre o serviço social e Núcleo foi muito importante para as tomadas de decisões (Gestora 3).

É uma parceira fundamental principalmente nas questões sociais da criança, referente à família, realidade vivida por ela. O serviço social entra como um elo entre "escola e família", trazendo um "porquê" e abrindo novas visões para determinado assunto e possivelmente novas soluções (Gestora 24).

UNESC, Criciúma, v. 5, n¹, janeiro/Junho 2016. Criar Educação - PPGE - UNESC 


\section{Criar Éducação}

ediunesc unesc

Como forma de construção gradativa do trabalho socioeducativo do serviço social, foram realizadas capacitações, reuniões e atividades pedagógicas que almejaram o enriquecimento dos profissionais da educação de forma interdisciplinar e coletiva.

A interdisciplinaridade não pode prescindir de uma boa dose de disciplinaridade, ou seja, é necessário que os profissionais envolvidos em trabalhos interdisciplinares funcionem como um pêndulo, que ele seja capaz de ir e vir: encontrar no trabalho com outros agentes, elementos para a (re) discussão do seu lugar e encontrar nas discussões atualizadas pertinentes ao seu âmbito interventivo os conteúdos possíveis de atuação interdisciplinar. Neste caso, estariam desenvolvendo uma parceria sobre um mesmo espaço profissional, onde diferentes ângulos de intervenção são produzidos, sem que uma proposta comum seja sistematizada (MELLO; ALMEIDA, 2000, apud CORRÊIA, 2013, p. 94).

Consoante ao exposto, a dimensão sociofamiliar deve ser analisada ao propormos ações articuladas e integradas com o contexto socioeconômico e cultural dos educandos, tendo em vista a corresponsabilidade do Estado, sociedade civil e família nos processos educativos dos indivíduos.

Esta forma de inserção do Serviço Social e de outros profissionais, formando uma equipe interdisciplinar para atuar na política de educação confirma a tendência atual das políticas sociais que atendem ao segmento da família, criança e adolescentes de criar vínculo com a educação (BOLORINO, 2007, p. 107).

Para uma das Gestoras entrevistadas na pesquisa, é

Muito importante a parceria entre $o$ núcleo e família, o diálogo é fundamental para qualquer decisões a serem resolvidas e temos que ter o conhecimento de tudo que envolve nossas crianças (suas relações vividas) (Gestora 25).

Para Amaro (2012, p. 17), ocorre a chamada da assistente social para o cenário educacional a partir do momento em que a questão social invade o espaço escolar e, todavia, surge a necessidade da "[...] complementação dos saberes disponíveis, na perspectiva de construir abordagens e respostas eficazes e efetivas às demandas sociais apresentadas, conjugada ao reconhecimento da qualificação técnica do assistente social para este trabalho, [...]". Conforme a autora supracitada, a escola tem o principal papel de promover e apoiar as dificuldades inerentes à relação escola e sociedade. 


\section{Criar Éducação}

De acordo com Almeida (2003), entende-se que a assistente social deve expressar a sua práxis profissional pelo enfrentamento das realidades sociais impostas pela lógica capitalista, que possibilite uma organização de trabalho coletivo na política educacional de tal maneira que articule com as exigências provenientes do contexto político, econômico e ideológico. Esta realidade é decorrente das múltiplas expressões da questão social, que invadem o cenário educacional e relacionam-se ao contexto da sociedade.

Consoante ao entendimento do autor supracitado, Martins (2001, p. 28) define que:

Considerando que é nesse contexto que se estabelece o trabalho do assistente social, ou seja, na apreensão da questão social e suas múltiplas expressões e na compreensão de como ela é experienciada pelos sujeitos em suas vidas cotidiana, pode-se afirmar que esse profissional tem plenas condições de mediatiza a problemática que se evidencia no espaço sócioocupacional.

De acordo com lamamoto (1997), o exercício da profissão, na contemporaneidade, requer, pois, ir além das rotinas institucionais e buscar apreender o movimento da realidade, a fim de detectar tendências e possibilidades nelas presentes. Concomitante ao mencionado, outra ação do Serviço Social foi a elaboração da documentação específica (formulários de visitas domiciliares, acompanhamento social) do Serviço Social a ser utilizada como instrumentais técnicos operativos. Tais instrumentais serviram de base e foram modificados ao longo do crescimento profissional e estrutural do serviço.

O processo de trabalho no Serviço Social é pautado no instrumental técnicooperativo utilizado por esse profissional. Esse instrumental não compreende apenas o arsenal de técnicas utilizadas para a efetivação do serviço, mas também o arsenal teórico-metodológico (conhecimento, valores, herança cultural, habilidades). Essa base teórico-metodológica é constituída pelos recursos essenciais que o assistente social aciona para exercer o seu trabalho, a fim de iluminar a leitura da realidade, direcionar melhor sua ação e moldá-la (IAMAMOTTO, 1997, p. 43).

Percebemos que o serviço social interliga-se diretamente com a educação, quando relacionamos as práticas socioeducativas (docentes) com as populações vulnerabilizadas e o comprometimento ético da assistente social em seu exercício profissional. Este projeto ético-político prevê ações de socialização, participação, universalização dos acessos em sua dimensão aos bens e serviços relativos aos 


\section{Criar Éducação}

programas e políticas sociais, quanto da riqueza socialmente produzida. Implica diretamente em um compromisso que tem por base a atividade investigativa e crítica da realidade; construção das particularidades e subjetividades dos usuários em prol de uma transformação social; compromisso com a família e sua democratização; participação dos usuários nas decisões políticas dos programas e espaços públicos; partilha e articulação com demais segmentos e políticas públicas (BARROCO, 1995).

O projeto ético-politico do Serviço Social tem por base a necessidade de transformação contínua adequada a cada metodologia de trabalho e o conjunto de instrumentais adotados. Na história do Serviço Social no Brasil, principalmente durante o período de reconceituação da profissão, a categoria profissional negava o instrumental na profissão porque, equivocadamente, entendia que representava o pragmatismo herdado pela influência norte americana. O importante era oferecer uma leitura de mundo a partir da leitura da realidade com foco em uma referência teórica. Portanto, a necessária unidade teoria/prática, que dá sustentação à transformação, fora desconsiderada em suas dimensões teórico-metodológica, ideopolítica e técnico-operativa. A questão era manter esta dissociação entre teoria/método/história, o que gera este instrumental criticado e, desta forma, apresenta o que é, por excelência para do serviço social, saber/fazer. O que podemos apresentar, na prática, é que os assistentes sociais retomam a questão da instrumentalidade como ferramenta de transformação do mundo por meio do conhecimento da teoria. Esta práxis interventiva do serviço social consolida o tripé da dimensão profissional: teoria-metodologia, ético-política e técnico-operativa (BATTINI, 1998).

Durante décadas o Serviço Social tem tentado demonstrar para todos que não é uma profissão estática, e sim altamente dialética e dinâmica. Desta forma, interage com diversos segmentos sociais na contribuição do bem-estar e promoção dos direitos humanos e sociais. Este processo pode estabelecer relações com diversas profissões como, por exemplo, na área da saúde, logística, educação, movimentos sociais, dentre outras. Com diversas estratégias diferentes, a profissional leva em consideração aspectos regionais, demandas e necessidades sociais nos territórios de sua atuação. Com seu caráter sociopolítico, crítico e interventivo, tem ampliado a ação em todos os espaços em que se transfiguram as 


\section{Criar Éducação}

desigualdades sociais que se originam do antagonismo entre a socialização da produção e a apropriação privada dos frutos do trabalho. O seu fazer profissional exige um conhecimento amplo sobre a realidade na sua complexidade, e em criar meios para transformá-la na direção do seu projeto político-profissional (PIANA, 2009).

Este conjunto de práticas adotado deve ser analisado e aplicado juntamente com o projeto ético-político da profissão. A dimensão ética da profissão está fundada na liberdade concebida historicamente como possibilidade de escolhas dentre alternativas concretas, evidenciando compromisso com a autonomia, a emancipação e a plena expansão dos indivíduos sociais. Esta perspectiva ética vincula o Serviço Social a um projeto societário que propõe a construção de uma nova ordem social, sem dominação e/ou exploração de classe, étnica, econômica e gênero. A partir das escolhas que o fundam, tal projeto afirma a defesa intransigente dos direitos humanos e a recusa do arbítrio e dos preconceitos, contemplando positivamente o pluralismo com hegemonia do trabalho. E é nesta lógica que a assistente social, inserida na política educacional, desenvolve o seu fazer profissional.

O Conselho Federal de Serviço Social orienta, por meio do parecer jurídico 23/00 de 22 de outubro de 2000, o desenvolvimento das seguintes funções da assistente social na política educacional:

- Pesquisa de natureza socioeconômica e familiar para a caracterização da população escolar;

- Articulação com instituições públicas, privadas, assistenciais e comunitárias com vistas ao encaminhamento de pais e alunos para atendimento de suas necessidades;

- Realização de visitas sociais com o objetivo de ampliar o conhecimento acerca da realidade sociofamiliar do aluno, de forma assisti-lo e encaminhá-lo adequadamente;

- Empreender e executar demais atividades pertinentes ao Serviço Social previstas pelos artigos 4 e 5 da Lei 8662/93.

Na tabela abaixo especificamos os principais objetivos e metodologia de trabalho utilizado no decorrer do desenvolvimento do trabalho do Serviço Social de 


\section{Criar Éducaçãa}

2009 até 2015, sendo inúmeras as possibilidades de contribuição e atuação do assistente social na área educacional, mais especificamente na Educação Infantil.

\begin{tabular}{|c|c|}
\hline \multicolumn{2}{|c|}{ AÇÕES COM PROFISSIONAIS DA EDUCAÇÃO E A REDE INTERSETORIAL } \\
\hline Objetivos & Metodologia \\
\hline $\begin{array}{l}\text { Planejar e elaborar estratégias com } \\
\text { vistas à perspectiva coletiva e } \\
\text { integrada dos profissionais }\end{array}$ & $\begin{array}{c}\text { Reuniões com a Equipe do Departamento } \\
\text { de Educação Infantil a fim de debater e } \\
\text { discutir sobre as situações familiares, bem } \\
\text { como orientações e encaminhamentos } \\
\text { realizados; }\end{array}$ \\
\hline $\begin{array}{c}\text { Assessorar Gestoras (es), } \\
\text { Supervisoras (es), } \\
\text { Administradoras(es) e Professoras } \\
\text { (es) dos NEl referentes às situações } \\
\text { familiares apresentadas; }\end{array}$ & $\begin{array}{c}\text { Visitas técnicas institucionais in loco e } \\
\text { diálogo com a Equipe Interdisciplinar por } \\
\text { meio do Roteiro de Estudo de Caso } \\
\text { (pedagogos, psicólogos, fonoaudiólogos, } \\
\text { nutricionistas); }\end{array}$ \\
\hline $\begin{array}{c}\text { Realizar estudo socioeconômico das } \\
\text { crianças matriculadas nos Núcleos de } \\
\text { Educação Infantil, propondo e } \\
\text { executando mecanismos que visem à } \\
\text { orientação e integração Família X } \\
\text { Núcleo; }\end{array}$ & $\begin{array}{c}\text { Visitas domiciliares, observação e } \\
\text { entrevistas Sociais com objetivo de } \\
\text { conhecer as condições em que vivem tais } \\
\text { sujeitos e apreender aspectos do cotidiano } \\
\text { das suas relações; }\end{array}$ \\
\hline 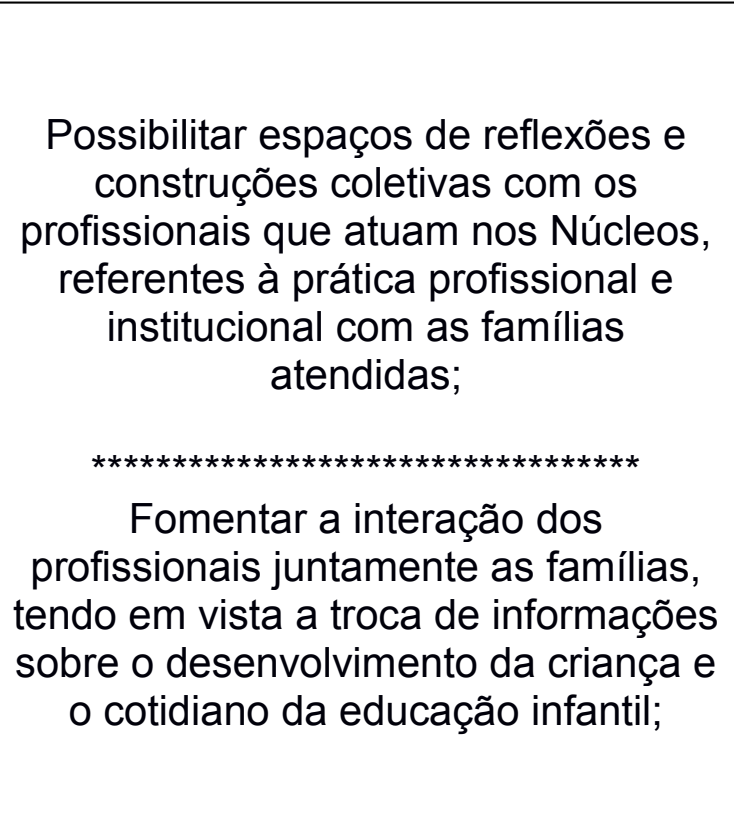 & 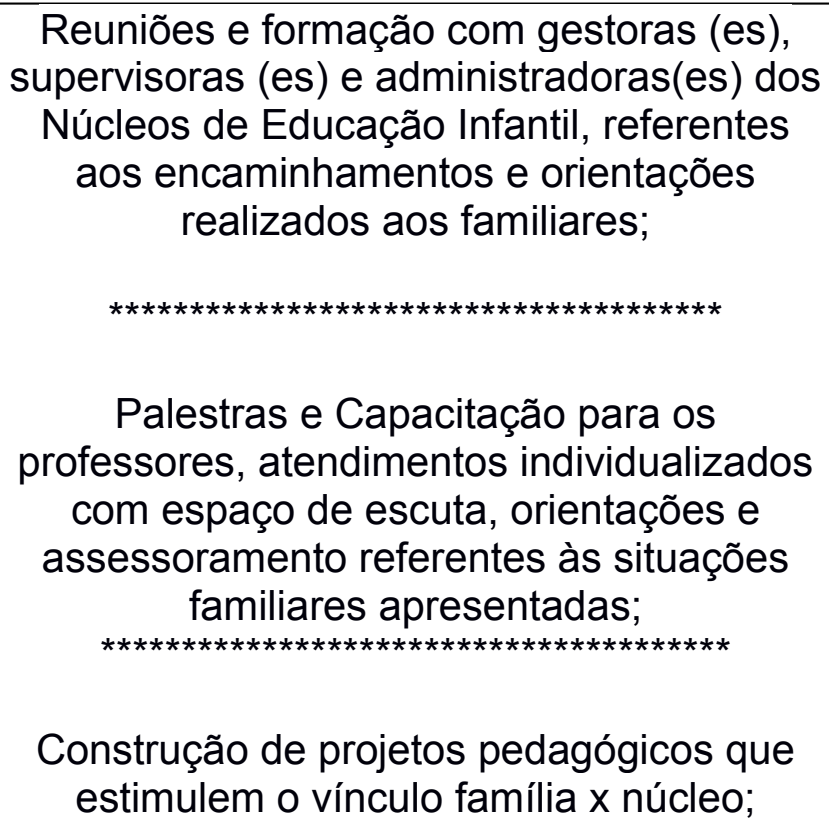 \\
\hline $\begin{array}{l}\text { Fortalecer o trabalho em rede e o } \\
\text { acompanhamento integrado das } \\
\text { famílias atendidas; }\end{array}$ & $\begin{array}{l}\text { Visitas domiciliares e /ou reuniões com a } \\
\text { rede intersetorial de atendimento à criança } \\
\text { e ao adolescente (Cras, Creas, Conselho } \\
\text { Tutelar,_Conselhos de Direitos, Poder } \\
\text { Judiciário e Ministério Público, Políticas }\end{array}$ \\
\hline
\end{tabular}

UNESC, Criciúma, v. 5, n¹, janeiro/Junho 2016. Criar Educação - PPGE - UNESC 


\section{Criar Éducaçãa}

\begin{tabular}{|c|c|}
\hline \multirow{2}{*}{ 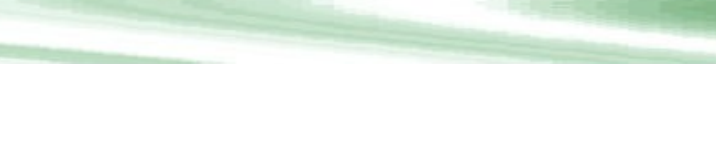 } & F \\
\hline & setoriais e entidades de atendimento); \\
\hline $\begin{array}{c}\text { Participar de Conselhos de Direitos } \\
\text { (Assistência Social, Saúde, Idoso, } \\
\text { CMDCA, Educação). }\end{array}$ & $\begin{array}{l}\text { Conselheira Titular no CMAS- Conselho } \\
\text { Municipal de Assistência Social; } \\
\text { Participação nas Reuniões dos Conselhos } \\
\text { de Direitos. }\end{array}$ \\
\hline \multicolumn{2}{|c|}{ AÇÕES COM AS FAMÍLIAS E EDUCANDOS } \\
\hline Objetivos & Metodologia \\
\hline $\begin{array}{c}\text { Fomentar o diálogo FAMÍLIA x } \\
\text { NÚCLEOS }\end{array}$ & $\begin{array}{c}\text { Projeto Grupo de Pais em parceria com o } \\
\text { Departamento de Educação Especial } \\
\text { (fonoaudiologia) 2015, com os profissionais } \\
\text { dos Núcleos e parceiros das políticas } \\
\text { setoriais do município; } \\
\text { Visitas Domiciliares com a Equipe da } \\
\text { Educação Infantil e/ou com a rede de } \\
\text { atendimento intersetorial (Cras, Creas, } \\
\text { Conselho Tutelar) conforme a situação } \\
\text { apresentada; } \\
\text { Atendimentos Individualizados as famílias } \\
\text { nos NEl ou na Secretaria Municipal de } \\
\text { Educação; } \\
\text { Encaminhamentos para os recursos da } \\
\text { comunidade; } \\
\text { Atendimento às famílias com crianças com } \\
\text { necessidades especiais e/ou dificuldade de } \\
\text { ensino/aprendizagem. }\end{array}$ \\
\hline
\end{tabular}

Fonte: Tabela adaptada do caderno de Orientações curriculares da Educação Infantil do município de Balneário Camboriú, anos 2013 e 2015.

Na pesquisa realizada no ano de 2013 com as gestoras dos núcleos de Educação Infantil, quando questionamos sobre as principais demandas relacionadas às crianças nos referidos núcleos, destacamos: questões de higiene e saúde; relacionamento com as famílias; situações de maus-tratos, principalmente negligência, faltas não justificadas, orientações quanto às novas configurações familiares, situações de vulnerabilidade social nas famílias e comportamento das crianças:

UNESC, Criciúma, v. 5, n¹, janeiro/Junho 2016. Criar Educação - PPGE - UNESC 


\section{Criar Éducaçãa}

Pais que se separam, mudam para outro município, não avisam, depois de muitas vezes retornam e querem a vaga novamente; crianças doentes, as quais os pais ficam contrariados em buscá-las (nos casos de febre alta) (Gestora 24).

Crianças que os pais negligenciam para levar ou buscar na escola; criança que vai sujinha para a escola; criança agressiva na escola; criança que não fala na escola; criança que não fica com a família no outro horário; criança que fica em outra escola no outro horário; criança rejeitada pela família, não é amada, não foi planejada, é um estorvo (Gestora 05).

Uma das ocorrências mais rotineiras relacionadas à criança/família, seria a estrutura familiar diferenciada (nova configuração familiar). Ex.: meus filhos, teus filhos (pai), nossos filhos (Gestora 15).

Mediante as observações e demandas apresentadas pelos NEI, sempre relacionadas a fatores familiares:

Percebeu-se a grande necessidade de aprimoramento, vínculo e aproximação, diálogo entre familiares e o contexto da Educação Infantil. Embora o contexto família e instituição sejam distintos, a criança é a mesma e é preciso favorecer o seu crescimento harmônico e o seu desenvolvimento integral (CORRÊIA, 2013, p. 94).

Entretanto, no decorrer das demandas apresentadas ao Serviço Social, percebeu-se que a maioria das práticas nos Núcleos de Educação Infantil, no que concernem às famílias resume-se a um breve contato por meio de entrevistas. No dia a dia, as famílias são convidadas a frequentá-lo somente em reunião de pais (geralmente no início e términos dos semestres), em festas e celebrações (Dia das Mães, Dia dos Pais, Festa Junina etc.), ou em entrevistas esporádicas, individuais, solicitadas pelo professor ou pela família, para tratar de um problema específico da criança. Contudo, o que se espera é que espaços coletivos de trocas de experiências entre as famílias e os Núcleos de Educação Infantil sejam proporcionados para que, quem cuida, possa redesenhar os papeis aos descobrir novos contornos sobre as práticas sociais e familiares.

Dessa forma, no cotidiano do trabalho do serviço social foram realizadas, nos anos de 2010 e 2011, encontros com os familiares nos Núcleos de Educação Infantil e, neste contexto, foram trabalhados os seguintes temas: importância da família no processo de educar no universo da Educação Infantil; corresponsabilidade na formação pessoal e social da criança; entendimento sobre o funcionamento e regimento interno dos Núcleos; Publicização e esclarecimento de outras políticas setoriais (Sistema de Garantia de Direito à Criança/Adolescente - Conselho Tutelar e suas atribuições, Política de Assistência Social -Centro de Referência em 


\title{
Criar Éducação
}

Assistência Social, CREAS - Centro de Referência Especializado em Assistência Social, Ações da Estratégia de Saúde e da Família).

No ano de 2015, o trabalho com as famílias ampliou-se em parceria com o Departamento de Educação Especial o Serviço Social, que passou a auxiliar no Projeto do Grupo de Pais, o qual teve início no ano de 2014, organizado pelos profissionais de fonoaudiologia e psicologia. A proposta do projeto é possibilitar aos pais/responsáveis ou familiares um espaço de escuta qualificada, orientação familiar, retirada de dúvidas e esclarecimentos sobre os processos de desenvolvimento infantil. No ano de 2015 ocorreram três encontros divididos entre os meses de março a julho em 9 núcleos de Educação Infantil.

A atuação junto aos familiares se torna exigência para garantia e acesso ao Direito a Educação de Qualidade, não somente na educação infantil, mas como nos outros níveis de modalidades de ensino (Fundamental, EJA- Educação para Jovens e Adultos, Ensino Médio...) (CORRÊIA, 2013, p. 94).

Ao abordar esta relação entre Educação e Serviço Social, Santos (2005, p. 44) pontua:

\begin{abstract}
Acredita-se que uma das maiores contribuições que o Serviço Social pode fazer na área educacional é a aproximação da família no contexto escolar. É intervindo na família, através do trabalho de grupo com os pais, que se mostra a importância da relação escolaaluno-família. O assistente social poderá diagnosticar os fatores sociais, culturais e econômicos que determinam a problemática social no campo educacional e, consequentemente, trabalhar comum método preventivo destes, no intuito de evitar que o ciclo se repita novamente.
\end{abstract}

Cabe ao profissional de serviço social deparar-se cotidianamente com uma realidade cada vez mais desafiadora, em que se torna visceral o aprimoramento intelectual constante, tendo em vista a legislação que garante os direitos e proteção às crianças e adolescentes e suas famílias, além da articulação intersetorial com as demais políticas sociais. Desta forma, assinala para o profissional uma gama de funções que se baseiam pela promoção e defesa intransigente dos direitos humanos e sociais com vistas à formação cidadã dos entes envolvidos em seu trabalho, sejam eles família, educandos e/ou profissionais da educação.

Nesse sentido, a assistente social inserida no espaço educacional tem, como um dos objetivos, atuar na perspectiva da promoção de espaços de 


\section{Criar Éducação}

desenvolvimento e aprendizagem dos educandos, bem como de prevenção de problemas relacionados a estes processos. Parte-se do princípio de que, ao trabalhar na perspectiva da formação de educadores, seja possível promover e prevenir questões relativas aos processos de desenvolvimento e aprendizagem das crianças dos Núcleos de Educação Infantil do município de Balneário Camboriú. Por isto, na pesquisa desenvolvida com as gestoras da educação infantil entre os temas propostos para futuras atividades formativas, foram citadas com prioridade: rede socioassistencial, importância da família na educação, atribuições do Conselho Tutelar, primeiros Socorros. Destacamos algumas falas das entrevistadas:

O esclarecimento do funcionamento desta rede de atendimento à criança. A função do Conselho Tutelar. Esclarecer a importância desses órgãos que são vistos por muitos como "meramente assistencialistas" (Gestora 23).

Direitos e Deveres da equipe com relação à criança. Ação do educador mediante a "família problemática". Palestra direta com os educadores, pois todos os profissionais necessitam destas informações (Gestora 11).

Tendo em vista o exposto, o profissional da área da educação depara-se, no cotidiano escolar, com situações que requerem aprimoramento intelectual e formação continuada em serviços, para que possa desenvolver seu papel no desenvolvimento do ensino/aprendizagem das crianças, suas famílias e dos profissionais da educação.

\section{Considerações finais}

A assistente social, na educação, deve intervir de forma crítica, propositiva, consciente e capaz de estabelecer as relações entre as condições objetivas da realidade e um processo reflexivo sobre as práticas institucionais, nas quais as crianças não sejam meros objetos de intervenção, mas sujeitos de direitos sociais e educacionais.

Os Parâmetros Curriculares da Educação Infantil, a Política Nacional de Educação, assim como a Política Nacional de Assistência Social e o Sistema Único de Assistência Social - SUAS preconizam um trabalho unificado e atenção integral à família. Ressaltamos, neste processo, a importância do diálogo e da construção conjunta e partilhada entre sociedade civil, comunidade, educação e demais 


\section{Criar Éducaçãa}

políticas públicas, bem como o acesso e o direito à educação de qualidade na primeira infância.

O trabalho do serviço social, nesta na política educacional, deve prezar pela promoção de espaços de desenvolvimento e aprendizagem aos educandos e educadores, bem como de prevenção de problemas relacionados a estes processos. Parte-se do princípio de que, ao trabalhar na perspectiva da formação de educadores, seja possível promover e prevenir questões relativas aos processos de desenvolvimento e aprendizagem das crianças dos Núcleos de Educação Infantil do município de Balneário Camboriú.

Cabe destacar a recente aprovação, na Comissão de Constituição de Justiça e Cidadania da Câmara de Deputados, do Projeto de Lei 3.688/2000, que propõe a inserção de assistentes sociais e psicólogas/os no quadro de profissionais da Educação em cada Unidade de Ensino. Atualmente segue para votação na plenária da Câmara e, se aprovado, seguirá para sanção presidencial. A aprovação deste Projeto de Lei é de suma importância para a consolidação da profissão nesta política, uma vez que as equipes multiprofissionais podem atuar na mediação das relações sociais/institucionais em articulação com as políticas setoriais e na melhoria da qualidade da política educacional.

Desta forma, cabe ao Serviço Social o desenvolvimento de ações socioeducativas, que identifiquem a educação como política social com o compromisso de garantir os direitos sociais na construção de uma educação pública de qualidade, que vise ao exercício da cidadania.

\section{Referências}

ALMEIDA, N. L. T. O Serviço Social na Educação: novas perspectivas sócioocupacionais, Belo-Horizonte, 2007. Disponível em: http://necad.paginas.ufsc.br/files/2012/07/O_Servico_Social_na_Educacao_perspecti vas_socio_ocupacionais1.pdf. Acesso em $1 \overline{0}$ de junho 2015.

. Serviço Social e Política Educacional: um breve balanço dos avanços e desafios desta relação. Palestra proferida no I Encontro de assistentes sociais na área da educação, no dia 28 de março de 2003, Belo horizonte.

AMARO, S. Serviço Social na Educação: bases para o trabalho profissional. Ed. UFSC, Florianópolis, 2012. 


\section{Criar Éducaçãa}

ARROYO, M. G. Pedagogias em movimento - o que temos a aprender dos

Movimentos sociais? Currículo sem Fronteiras, v.3, n.1, p.28-49, jan./jun. 2003.

Disponível em: <HTTP://www.curriculosemfronteiras.org/vol3issarticles/arroyo.pdf>.

Acesso em: 10 nov. 2013.

BATTINI, O. Assistência Social Constitucionalização. Representação Práticas. Veras: São Paulo, 1998.

BARROCO, M.L.S. A moralização da questão social e o neoliberalismo. $8^{\circ}$ CBAS. Cadernos de Comunicações. Salvador, Bahia, 1995.

BOLORINO, E. C. M.. Educação e Serviço Social: Elo para Construção da Cidadania. São Paulo: PUC, 2007.

BRASIL. Lei $\mathbf{n}^{\circ}$ 9.364, de 20 de dezembro de 1996. Lei de Diretrizes e Bases da Educação Nacional - LDB. Lisponível em: <http://www.planalto.gov.br/ccivil_03/LEIS/L9394.htm.>. Acesso em: 05 jul. 2015.

. Constituição da República Federativa do Brasil. Brasília: Senado

Federal, $1988 . \quad$ Disponível em: <http://www.planalto.gov.br/ccivil_03/constituicao/constituicao.htm>. Acesso em: 20 fev. 2013.

MEC/SEF,Brasília,

Referencial Curricular Nacional para 1998b. Disponível

Educação Infantil. www.oei.es/inicial/curriculum/rcnei_Brasil1.pdf. Acesso em:10 jul. 2015

Lei $\mathbf{n}^{\circ} \mathbf{8 . 0 6 9}$ de 13 de julho de 1990. Estatuto da Criança e do Adolescente- ECA. Disponível em:

<http://www.planalto.gov.br/CCIVIL_03/leis/L8069.htm.>. Acesso em: 05 jul. 2015.

. Diretrizes Curriculares Nacionais para Educação Infantil.

MEC/SEB, Brasília, 2010. Disponível em:

$<$ file:///C:/Users/Usuario/Downloads/diretrizescurriculares_2012.pdf.>. Acesso em: 10 jul. 2015.

. Lei $\mathbf{n}^{\circ}$ 12.594, de 18 de janeiro de 2012. Institui o Sistema Nacional de Atendimento Socioeducativo (Sinase), Brasília, 2012.

CORRÊIA, M. A. Orientações curriculares Municipais de Balneário Camboriú_ Educação Infantil- Editora: Nova Letra, 2011 a 2013.

FERNANDES, M. Z. A educação infantil como um projeto da comunidade: crianças, educadores e pais nos novos serviços para a infância e a família: A experiência de San Miniato. Educar em Revista, n.43, p. 257-263, jan/mar. 2012. Disponível em: <http://www.scielo.br/pdf/er/n43/n43a17.pdf>.Acesso em: 08 jul 2015 


\section{Criar Éducação}

GENTILI, P. O direito à educação e as dinâmicas de exclusão na América Latina. Educ.Soc., Campinas, vol. 30,n. 109,p.1059-1079,set/dez.2009.Disponível em: <http://www.cedes.unicamp.br>. Acesso em: 30 set. 2012.

IAMAMOTO, M. V. O Serviço Social na contemporaneidade: dimensões históricas, teóricas e ético-políticas. Fortaleza: Cress-CE, 1997.

M. V. O Serviço Social na contemporaneidade: trabalho e formação profissional. São Paulo, Cortez, 2005.

MACHADO, M. L. A. Educação infantil e sócio-interacionismo. In: OLIVEIRA, Zilma de (org). Educação infantil: muitos olhares. 8.ed. São Paulo: Cortez, 2008, p.25-5

MARTINS, E. B. C. Serviço Social: mediação escola e sociedade. Dissertação de Mestrado. Franca: UNESP, 2001. Disponível em : <http://www.unitoledo.br . Acesso em 30 jul. 2015.

OLIVEIRA, Z. R. Educação Infantil: fundamentos e métodos. São Paulo: Cortez, 2002.

PIANA, M. C. Serviço Social e Educação: olhares que se entrecruzam. Revista Serviço Social e Sociedade, Franca, v.18,n 2, p.182-206, 2009.

SANTOS, A.M. A Escola como espaço de atuação para o Assistente Social: Trabalhando com grupos. Trabalho Final de Graduação - TFG. Centro Universitário Franciscano, UNIFRA, 2005. 